\title{
Effect of beetroot juice on lowering blood pressure in free-living, disease-free adults: a randomized, placebo-controlled trial
}

\author{
Leah T Coles ${ }^{*}$ and Peter M Clifton
}

\begin{abstract}
Background: The consumption of beetroot juice on a low nitrate diet may lower blood pressure (BP) and therefore reduce the risk of cardiovascular events. However, it is unknown if its inclusion as part of a normal diet has a similar effect on BP. The aim of the study was to conduct a randomized controlled trial with free-living adults to investigate if consuming beetroot juice in addition to a normal diet produces a measureable reduction in BP.

Method: Fifteen women and fifteen men participated in a double-blind, randomized, placebo-controlled, crossover study. Volunteers were randomized to receive $500 \mathrm{~g}$ of beetroot and apple juice (BJ) or a placebo juice (PL). Volunteers had BP measured at baseline and at least hourly for 24-h following juice consumption using an ambulatory blood pressure monitor (ABPM). Volunteers remained at the clinic for 1-h before resuming normal non-strenuous daily activities. The identical procedure was repeated 2-wk later with the drink (BJ or PL) not consumed on the first visit.
\end{abstract}

Results: Overall, there was a trend $(P=0.064)$ to lower systolic blood pressure (SBP) at 6-h after drinking BJ relative to PL. Analysis in men only $(n=13)$ after adjustment for baseline differences demonstrated a significant $(P<0.05)$ reduction in SBP of $4-5 \mathrm{mmHg}$ at 6-h after drinking BJ.

Conclusions: Beetroot juice will lower BP in men when consumed as part of a normal diet in free-living healthy adults.

Trial registration: anzctr.org.au ACTRN12612000445875

Keywords: Beetroot, Blood pressure, Hypertension, Inorganic nitrate

\section{Background}

In the last 20 years or so there has been renewed interest in the potential of inorganic nitrate $\left(\mathrm{NO}_{3}^{-}\right)$to control blood pressure in humans [1]. Dietary inorganic nitrate is absorbed rapidly and completely in the proximal small intestine with $100 \%$ bioavailability [2]. Approximately $25 \%$ of the nitrate circulating in the plasma is then concentrated in the salivary glands and secreted into the mouth where around $20 \%$ (or $\approx 5-8 \%$ of intake) is converted to nitrite $\left(\mathrm{NO}_{2}^{-}\right)$by commensal bacteria on the tongue and subsequently swallowed [3]. Upon reaching the stomach the $\mathrm{NO}_{2}^{-}$is either absorbed directly or reduced to nitric oxide (NO) as a result of the acidic

\footnotetext{
* Correspondence: leah.coles@bakeridi.edu.au

Nutritional Interventions Laboratory (LC, PC), Baker IDI Heart \& Diabetes Institute, Melbourne, Australia
}

environment of the stomach [3-5]. Endogenously produced $\mathrm{NO}$ and $\mathrm{NO}_{2}^{-}$are vasoprotective agents with the ability to increase vasodilation, decrease blood pressure (BP) and improve cardiovascular function [6]. Reduced endogenous NO production is associated with hypertension [7] and there is evidence to support the hypothesis that the $\mathrm{NO}$ and $\mathrm{NO}_{2}^{-}$produced as a result of dietary $\mathrm{NO}_{3}^{-}$could induce health benefits [8].

The individual daily intake of dietary nitrate has been estimated to be $\approx 81-106 \mathrm{mg} / \mathrm{d}$ (not including loses from washing, peeling and cooking) in the typical Western diet, with vegetables contributing approximately $80 \%$ of this value $[9,10]$. The vegetables with the highest nitrate contents ( $>250 \mathrm{mg} / 100 \mathrm{~g}$ fresh weight) are celery, cress, chervil, lettuce, red beetroot, spinach and rocket [11]. Green leafy vegetables have recently been shown to be 
among the foods most beneficial in the prevention of coronary heart disease and ischemic stroke $[12,13]$. This effect has been postulated to be due to the high inorganic $\mathrm{NO}_{3}^{-}$content of these vegetables [14-16].

Beetroot is a rich source of dietary $\mathrm{NO}_{3}^{-}[11]$ and a number of studies have investigated its potential for reducing blood pressure in humans [8,17-20], which appears to be more potent in men.

Although beetroot appears to be a promising means of lowering blood pressure, previous studies in free-living subjects have been small in size and routinely used a controlled diet in combination with administering the beetroot juice. It is not clear whether a blood pressurelowering effect may be seen when beetroot juice is consumed on top of a normal diet. The present study examines the use of beetroot juice as a means of regulating blood pressure in free-living individuals whilst not imposing any dietary restrictions.

\section{Methods}

\section{Materials}

The nitrate was administered as Sunraysia Beetroot and Apple Juice ( $72 \%$ beetroots and $28 \%$ apples) (BJ), containing $15 \mathrm{mmol}$ nitrate/L (data supplied by The Sunraysia Natural Beverage Company, Melbourne, VIC). The placebo (PL) consisted of an apple juice concentrate base matched to the BJ for sweetness (sucrose) and colour (carmine red and rubini red). Both the BJ and PL were supplied by The Sunraysia Natural Beverage Company, Melbourne, VIC.

\section{Intervention study subjects}

A total of thirty healthy volunteers (15 F, $15 \mathrm{M})$ were recruited for the trial from Melbourne, Australia. The primary inclusion criterion was a systolic blood pressure (SBP) of greater than $120 \mathrm{mmHg}$ at the time of administering the first treatment. Subjects who were pregnant/ lactating, on blood pressure medication or had been diagnosed with diabetes mellitus were excluded from participating. Written informed consent was obtained from all volunteers prior to participation in the study. The study was approved by the Alfred Research Human Ethics Committee (377/11) and took place in January 2012.

\section{Study design}

The study was designed as a double-blind, randomized, crossover, intervention trial in which volunteers were asked to consume $500 \mathrm{~g}$ of either BJ or PL on a single occasion. No dietary restrictions were placed on the subjects prior to visits, in the $24 \mathrm{~h}$ period following consumption of the BJ or PL or during the 2-wk washout period.
Subjects arrived at the clinic at approximately $0800 \mathrm{~h}$ on the day of treatment in a non-fasted state (light breakfast only), having performed no more than light physical activity on the study day. Subsequent to anthropometric measurements (height and body weight) and a rest period of 5-min, subjects were fitted with an ABPM (Meditech ABM-04, Budapest, Hungary) to measure SBP, diastolic blood pressure (DBP) and pulse rate. Three baseline blood pressure measurements were recorded by the ABPM at intervals of 2-min apart with the subject in a seated position. If the subject recorded an average baseline SBP of greater than $120 \mathrm{mmHg}$ they were randomly assigned by computer software to receive the $\mathrm{BJ}$ or PL, which was then consumed immediately in unmarked glasses over the course of 5 to $10-\mathrm{min}$. Subjects remained in a seated and unfed state at the clinic for 1-h post-drink consumption, during which time three BP measurements were taken by the ABPM. Subjects then left the clinic and resumed normal daily tasks whilst continuing to wear the ABPM for a further 23-h. Subjects were instructed not to undertake any moderate or intense physical activity (e.g. brisk walking, cycling, running, gym workout) during this time and to loosely hang their cuffed arm by their side during BP readings. ABPM measurements were automatically taken halfhourly during the active period $(0700 \mathrm{~h}-2300 \mathrm{~h})$ and hourly during the remaining passive period. An activity log book was also given to volunteers to record actual awake and sleeping times and the times of any 'unusual' events that may have effected BP measurements (e.g. getting a parking ticket, running late for a bus). Subjects returned to the clinic 24-h following the treatment to have the ABPM removed. Subjects returned to the clinic $2-w$ later, and repeated the same methodology with the drink (BJ or PL) not consumed on the first visit.

\section{Statistical analyses}

Power calculations were based on a previous similar study [8] where the SD of the change in BP at 2.5-h was $6 \mathrm{mmHg}$. With 30 participants completing the present study using a crossover design it was calculated that a $3.2 \mathrm{mmHg}$ difference (or $4.7 \mathrm{mmHg}$ difference in men alone) in BP could be detected with $80 \%$ power $(P<0.05)$.

The data from the BP monitors was transferred into Microsoft Excel (Microsoft Corp., Redmond, WA) and then analyzed using statistical software (SPSS 18, IBM Corp., Armonk, NY). The ABPM provided all raw data as well as averages for active/ day time $(0600-2259 \mathrm{~h})$ or passive / night time (2300 to 0559 h) periods. Averages were calculated for baseline BP from the 3 measures taken, over 3 to $4-\mathrm{h}, 6$ to 7 -h or 23 to $24-\mathrm{h}$ after the drink. Depending on the number of successfully recorded measurements in each period, there may have 
been 1-3 values in each of these time periods. Repeated measures analysis of covariance was used with a covariate of the difference between baseline blood pressure on the two days (ANCOVA). A separate analysis with a post hoc removal of outliers ( $>3 \mathrm{SD}$ drop in blood pressure after ingestion of the juice) was also performed. Given the previous results showing men showed greater effects, a planned analysis in men only was performed. In all cases, differences were deemed significant at $P<0.05$.

\section{Results}

Satisfactory blood pressure recordings were reported by the 15 men and 15 women (Table 1) who completed the study and no adverse effects were reported from drinking the intervention juices. Subjects ranged in age from $23-68$ y. Subjects were generally healthy with none of the male subjects and approximately half of the female subjects not medicated (Table 2). The number of measures of blood pressure over the 24-h ranged from 31 to from 44 measurements.

Overall, there was no significant difference in treatments for any parameter except day time pulse pressure (difference between systolic and diastolic pressures) of $1 \mathrm{mmHg}$ higher on the PL treatment (Table 3). There were no statistically significant differences between the juices in average day time or night time blood pressures or heart rate.

Individual BP changes from baseline after each treatment showed a drop of $4.6 \mathrm{mmHg}$ with BJ and $3.4 \mathrm{mmHg}$ with PL at 3-h, $6.2 \mathrm{mmHg}$ and $2.2 \mathrm{mmHg}$ respectively at 6-h and $4.5 \mathrm{mmHg}$ and $2.3 \mathrm{mmHg}$ respectively, at 24-h. Statistically the 6-h difference was a trend overall $(P=0.064)$, with men showing a difference of $-4.7 \mathrm{mmHg}, \quad(P=0.1)$ and women a difference of $-2.5 \mathrm{mmHg}(P=0.5)$. In the planned ANCOVA in men only $\mathrm{BJ}$ treatment was significantly different from placebo $(P=0.007)$ and a treatment covariate interaction was observed $(P=0.024)$. In those subjects with little variation in baseline BP measures there was a clear effect of BJ. In those subjects with a large variation in baseline

Table 1 Baseline characteristics of study subjects ${ }^{1,2}$

\begin{tabular}{|c|c|c|c|c|c|c|}
\hline \multirow[b]{3}{*}{ Characteristic } & \multicolumn{6}{|c|}{ Subjects } \\
\hline & \multicolumn{2}{|c|}{ All $(n=30)$} & \multicolumn{2}{|c|}{ Male $(n=15)$} & \multicolumn{2}{|c|}{ Female $(n=15)$} \\
\hline & Mean & SEM & Mean & SEM & Mean & SEM \\
\hline$\overline{\text { Age }(y)^{1}}$ & 42.5 & 3.4 & 36.2 & 2.9 & 48.9 & 3.1 \\
\hline BMI $\left(\mathrm{kg} / \mathrm{m}^{2}\right)^{1}$ & 28.2 & 1.3 & 28.7 & 1.3 & 27.6 & 1.2 \\
\hline $\mathrm{SBP}(\mathrm{mmHg})^{2}$ & 132.4 & 1.6 & 132.1 & 2.2 & 132.7 & 2.3 \\
\hline $\mathrm{DBP}(\mathrm{mmHg})^{2}$ & 81.1 & 1.2 & 79.6 & 1.8 & 82.6 & 1.7 \\
\hline
\end{tabular}

${ }^{1}$ Values for Age and BMI are means and their SEM on day of first treatment.

${ }^{2}$ Values for SBP and DBP are pooled means of the average baseline measures across the two treatment days and their pooled SEM.

BMI, body mass index; DBP, diastolic blood pressure; SBP, systolic blood pressure.
BP measures, SBP did not change with BJ and increased with PL, although the difference between the drinks was smaller.

In a post hoc analysis of outliers, those men with large drops in BP ( $\geq 20 \mathrm{mmHg}$ SBP) at 6-h following drink consumption on either treatment $(n=2)$ were removed. In the remaining 13 men the 6-h difference between PL and BJ of $4.9 \mathrm{mmHg}$ was statistically significant $(P=0.042)$.

\section{Discussion}

It has been postulated that the inclusion of dietary nitrates in the form of beetroot-derived foods may be useful in the regulation of normal BP due their high inorganic $\mathrm{NO}_{3}^{-}$content. The present contribution is the first study, to the authors' knowledge, to examine the effect of beetroot juice on BP in free-living individuals in the absence of dietary restrictions, such as a low nitrate diet. Dietary restrictions in studies with beetroot juice and BP remove confounding dietary factors that may have an effect (negative or positive) on BP, thus making interpretation of study results more straightforward. The drawback, however, is that beetroot juice as a nutritional intervention to regulate BP would likely be consumed as part of a normal diet, not as part of a low nitrate diet or in the absence of other dietary components (e.g. coffee, alcohol, black tea) that may affect BP [21-23]. It was therefore uncertain whether there is any clinically relevant benefit from beetroot juice supplementation on $\mathrm{BP}$ in the unregulated home environment.

Unsurprisingly, there was a large degree of variation in the $\mathrm{BP}$ readings for a given individual both across the two measurement days and throughout each day. This may have been a result of the free-living nature of the study. Whilst there was no significant difference in baseline SBP or DBP between men and women, the trend of $\mathrm{BJ}$ lowering $\mathrm{BP}$ was stronger in men than in women and a planned separate analysis in men showed that BJ lowered SBP by $4-5 \mathrm{mmHg}$ at 6 -h after ingestion. It is uncertain whether these differences between the sexes was a result of gender per se, or whether the older age of the women $(48.9 \pm 3.1 \mathrm{y})$ compared to the men $(36.2 \pm 2.9 \mathrm{y})$ may have influenced the variation seen. It is also notable that approximately half of the women $(n=8)$ who participated in the study took prescription medication, whilst none of the men did. The crossover design of the study should have eliminated any individual variation in blood pressure due to any medication taken daily on the two $24 \mathrm{~h}$ periods that BP was measured. However, the possibility of the effect of medication or diet (e.g. sodium intake) on the outcomes of the trial cannot be discounted and ideally the experiment should be repeated in nonmedicated individuals and the dietary intake recorded. Two of the studies in the literature investigating beetroot 
Table 2 Number of study subjects normally taking medication / nutritional supplements, exercising regularly, drinking alcohol and smoking cigarettes

\begin{tabular}{lccc}
\hline & \multicolumn{2}{c}{ Number of subjects partaking } \\
\cline { 2 - 4 } Medication / Supplement / Lifestyle factor & All $(\boldsymbol{n}=\mathbf{3 0})$ & Male $(\boldsymbol{n}=\mathbf{1 5})$ & Female $(\boldsymbol{n}=\mathbf{1 5})$ \\
\hline Exercise & 22 & 12 & 10 \\
Alcohol & 22 & 2 & 10 \\
Cigarettes & 3 & 6 & 1 \\
Vitamins / fish oil & 14 & 15 & 7 \\
No prescription medication & 22 & 0 & 8 \\
Prescription medication & 8 & - & 5 \\
Oral contraceptives / estrogens & 5 & - & 4 \\
Cholesterol & 4 & - & 2 \\
Antidepressants & 2 & - & 2 \\
Osteoporosis drugs & 2 & - & 2 \\
Asthma drugs & 2 & & 5 \\
\hline
\end{tabular}

juice and BP that used both men and women did not report results by gender $[8,20]$. The third such study, by Kapil and colleagues tested $24 \mathrm{mmol}$ of $\mathrm{KNO}_{3}$ (or $\mathrm{KCl}$ ) in capsules in a double-blind crossover study in 8 males (baseline BP 126/73 mmHg) and 12 females (baseline BP $102 / 67 \mathrm{mmHg}$ ) and found that the $\mathrm{KNO}_{3}$ lowered systolic BP by $9.4 \mathrm{mmHg}$ at $6-\mathrm{h}$ and diastolic by $6 \mathrm{mmHg}$ at 2.5-h (systolic lowering was $6 \mathrm{mmHg}$ at this time point) [19]. Females had no significant fall in blood pressure (3-4/5 mmHg reduction only) despite absolute plasma nitrite rises twice those seen in men. Some of these differences may have been due to the large difference in baseline BP (difference in SBP $=24 \mathrm{mmHg}, P<0.001$ ) between men and women in that particular study as it was noted that decreases in $\mathrm{BP}$ were correlated with baseline BP $(r=0.66$ to 0.7$)$. In the present study, baseline BP readings were remarkably similar between men (132/80 $\pm 2.2 / 1.8 \mathrm{mmHg})$ and women $(133 / 83 \pm 2.3 / 1.7 \mathrm{mmHg})$. It is difficult to ascertain if there is in fact a genderspecific response to dietary nitrates.

The drop of 4-5 mmHg observed in the study reported here at 6 -h after consumption in men is smaller and with a later peak drop in BP than in other controlled studies with beetroot juice. In an open-label and unblinded study, Webb et al. demonstrated that $500 \mathrm{ml}$ of beetroot juice containing $45 \mathrm{mmol} / \mathrm{L}$ (or $2.79 \mathrm{~g} / \mathrm{L}$ ) of $\mathrm{NO}_{3}^{-}$lowered BP by a maximum of $10 / 4.8 \mathrm{mmHg}$ at approximately 3 - $\mathrm{h}(\mathrm{p}<0.001 ; \mathrm{n}=9 \mathrm{~m}, 5 \mathrm{f}$; mean baseline BP: $109 / 71 \mathrm{mmHg}$ ) and the effect persisted in SBP for 24-h [8]. Although it was stated that the effect on BP was related to the increase in plasma nitrite this only accounted for about $7 \%$ of the variance. In that study, volunteers were measured seated in clinic and asked to refrain from caffeine-containing drinks or foods with a

Table 3 Systolic blood pressure, diastolic blood pressure and pulse pressure of subjects during the active and passive periods in the 24-h following ingestion of beetroot juice and placebo juice ${ }^{1}$

\begin{tabular}{|c|c|c|c|c|c|c|}
\hline \multirow[b]{3}{*}{ Measurement } & \multicolumn{6}{|c|}{ Mean value over $24-h^{1}$} \\
\hline & \multicolumn{2}{|c|}{ All subjects $(n=30)$} & \multicolumn{2}{|c|}{ Male $(n=15)$} & \multicolumn{2}{|c|}{ Female $(n=15)$} \\
\hline & Placebo & Beetroot & Placebo & Beetroot & Placebo & Beetroot \\
\hline \multicolumn{7}{|l|}{ Active period (awake) } \\
\hline $\mathrm{SBP}(\mathrm{mmHg})$ & $128.3 \pm 1.9$ & $126.6 \pm 1.5$ & $129.6 \pm 3.1$ & $128.7 \pm 2.3$ & $127.0 \pm 2.3$ & $124.6 \pm 1.8$ \\
\hline $\mathrm{DBP}(\mathrm{mmHg})$ & $77.8 \pm 1.7$ & $77.6 \pm 1.3$ & $77.1 \pm 2.5$ & $77.5 \pm 2.0$ & $78.4 \pm 2.3$ & $77.9 \pm 1.8$ \\
\hline Pulse pressure $(\mathrm{mmHg})^{2}$ & $50.6 \pm 1.3^{\mathrm{a}}$ & $49.1 \pm 1.3^{b}$ & $52.5 \pm 2.1$ & $51.2 \pm 2.0$ & $48.7 \pm 1.6$ & $46.9 \pm 1.4$ \\
\hline \multicolumn{7}{|l|}{ Passive period (asleep) } \\
\hline $\mathrm{SBP}(\mathrm{mmHg})$ & $111.0 \pm 2.2$ & $113.3 \pm 2.0$ & $111.6 \pm 2.6$ & $117.0 \pm 2.9$ & $110.5 \pm 3.5$ & $109.5 \pm 2.4$ \\
\hline $\mathrm{DBP}(\mathrm{mmHg})$ & $62.8 \pm 1.3$ & $65.4 \pm 1.3$ & $62.1 \pm 2.1$ & $65.9 \pm 1.9$ & $63.5 \pm 1.6$ & $65.0 \pm 1.8$ \\
\hline Pulse pressure $(\mathrm{mmHg})^{2}$ & $48.2 \pm 1.5$ & $47.8 \pm 1.4$ & $49.5 \pm 1.8$ & $51.2 \pm 1.9$ & $47.0 \pm 2.4$ & $44.5 \pm 1.5$ \\
\hline
\end{tabular}

${ }^{1}$ Values are means \pm SEM. Values with different superscript letters indicate that differences between beetroot juice and placebo are significant, $P<0.05$.

${ }^{2}$ Pulse pressure refers to SBP minus DBP.

DBP, diastolic blood pressure; SBP, systolic blood pressure. 
high nitrate content (green leafy vegetables, beetroot) for $12-\mathrm{h}$ prior to the study and were fasting on the morning of the study.

More recently, Hobbs and workers [18] conducted a single-blind, randomized, controlled, crossover study and observed an almost dose-dependent drop of 20.5/14.6 $\mathrm{mmHg}$ at 2-3 $\mathrm{h}$ postprandial using beetroot juice containing $5.7 \mathrm{mmol} \mathrm{NO}_{3}^{-}$relative to the control (water), and 22.2/18.3 $\mathrm{mmHg}$ with twice that dose of $\mathrm{NO}_{3}^{-}$. Once again, subjects $(n=18 \mathrm{M}$, mean baseline BP: $131 / 82 \mathrm{mmHg}$ ) were fasted for $12-\mathrm{h}$ and the diet was restricted (no alcohol or and caffeine) in the 24-h prior to the test and were provided with a standard evening meal for the night before each visit and for the lunch and dinner of the study day. Subjects were also instructed not to take any dietary supplements, vitamins or minerals for 1-wk prior to the study or during the intervention period. Subjects were also required to meet a large number of inclusion criteria including not smoking, not exercising more than 3 times / wk $(<20 \mathrm{~min} / \mathrm{ses}-$ sion) and not consuming $>150 \mathrm{ml}$ alcohol / wk. The highly controlled nature of this study may have been responsible for the particularly large decreases in BP observed.

Two other studies have also reported a reduction in BP from beetroot juice, but the number of study participants was small. In an open-label study in 9 volunteers (gender not stated) Kapil et al. tested $250 \mathrm{ml}$ beetroot juice (5.5 mmol $\left.\mathrm{NO}_{3}^{-}\right)$relative to a water control [19]. A peak reduction in SBP of $5.4 \pm 1.5 \mathrm{mmHg}$ was found, whilst diastolic blood pressure changes were not significant. Both plasma $\mathrm{NO}_{3}^{-}$and $\mathrm{NO}_{2}^{-}$were elevated for 3-h following beetroot juice ingestion. In another study, Vanhatalo et al. tested 8 volunteers $(n=5 \mathrm{M}, 3 \mathrm{~F}$; baseline SBP and DBP of $127 \pm 6$ and $72 \pm 5 \mathrm{mmHg}$, respectively) with 0.51 beetroot juice daily, in two equal doses in the morning and evening, for 5 days against a placebo (low-calorie blackcurrant juice cordial with negligible $\mathrm{NO}_{3}^{-}$content) in a randomized, crossover study with a 10-d washout period [20]. On day 5 of the treatment, SBP and DBP were reduced on the beetroot juice by approximately $4 \%$ relative to the placebo. In the present study, a single dose of BJ was administered and the effect measured over the next 24-h. It is possible that a cumulative beneficial effect may occur if the BJ was consumed on a daily basis. Further studies are needed to confirm if this is the case and to determine what the optimal daily dose should be in free-living adults. The BJ and PL used here contained $28 \%$ apple juice. It is plausible that the apple juice may have had some contrary effect on BP, thus partially negating or cancelling the effect of the beetroot on lowering BP. While the literature actually supports a BP lowering effect of quercetin (found in large amounts in apples) [24], the experiment could be repeated using pure beetroot juice to eliminate any possible effect of other components present in the BJ.

As a higher baseline BP has been correlated with a larger reduction in BP following $\mathrm{BJ}$ ingestion [19] it is possible that hypertensive patients could benefit more from beetroot juice consumption than the group of subjects studied here. The volunteers used here were healthy, but unlike a number of other studies, they included both genders, a broad age range $(23-68 \mathrm{y})$ and exhibited higher baseline $\mathrm{BP}$ values (mean 132/81 $\pm 1.6 / 1.2 \mathrm{mmHg}$ ). The results presented here are therefore more generalizable to the population as a whole in Western countries, especially given the free-living nature of the study. Using an even larger group of volunteers, with different characteristics (e.g. on average, lower / higher BMI or age) would be further beneficial, as the group studied here were on average middle-aged and slightly overweight. Although it was not undertaken in the present study, it would also be preferable to measure plasma $\mathrm{NO}_{3}$ levels before and after consumption of the $\mathrm{BJ}$ and PL in order to establish a causative relationship between the $\mathrm{NO}_{3}$ present in beetroot and the effect on plasma $\mathrm{NO}_{3}$ levels leading to a reduction in BP. This would assist in eliminating other possible causes of the effect seen, such as the diuretic property of beetroot.

\section{Conclusions}

In conclusion, it was demonstrated here that in freeliving people consuming an unrestricted diet and a single dose of $500 \mathrm{~g}$ of beetroot and apple juice, a trend to lower blood pressure by $4-5 \mathrm{mmHg}$ at 6 -h was observed (significant only in men after adjustment for baseline variation). A reduction in SBP in the magnitude of $5 \mathrm{mmHg}$ has been correlated to a cardiovascular mortality reduction of approximately $10 \%$ at the population level [25]. Additional studies with beetroot and apple juice in larger groups of free-living men and women are needed to fully assess the efficacy such a dietary intervention at a public health level in the treatment of cardiovascular disease and to determine the exact mechanism of action.

\section{Abbreviations}

ABPM: Ambulatory blood pressure monitor; BJ: Beetroot and apple juice; BP: Blood pressure; DBP: Diastolic blood pressure; PL: Placebo; SBP: Systolic blood pressure.

\section{Competing interests}

The authors declare that they have no competing interests. The Sunraysia Natural Beverage Company (Melbourne, VIC) funded this study but was not involved in its design or the collection, analysis or interpretation of data.

\section{Authors' contributions}

PC designed the study, analysed the data and had primary responsibility for final content. LC conducted the study and drafted the report. Both authors read and approved the final manuscript. 


\section{Acknowledgements}

The authors would like to acknowledge Claire Galbraith (Baker IDI Heart \& Diabetes Institute) for assistance with data collection. The Sunraysia Natural Beverage Company (Melbourne, $\mathrm{VIC}$ ) funded this project and supplied the juice and placebo juice used. This study was supported in part by the Victorian Government's OIS Program.

Received: 29 June 2012 Accepted: 7 December 2012

Published: 11 December 2012

\section{References}

1. Gilchrist M, Shore AC, Benjamin N: Inorganic nitrate and nitrite and control of blood pressure. Cardiovasc Res 2011, 89:492-498.

2. van Velzen AG, Sips AJ, Schothorst RC, Lambers AC, Meulenbelt J: The oral bioavailability of nitrate from nitrate-rich vegetables in humans. Toxicol Lett 2008, 181:177-181.

3. Lundberg JO, Weitzberg E, Lundberg JM, Alving K: Intragastric nitric oxide production in humans: measurements in expelled air. Gut 1994, 35:1543-1546.

4. Benjamin N, O'Driscoll F, Dougall H, Duncan C, Smith L, Golden M, McKenzie H: Stomach NO synthesis. Nature 1994, 368:502.

5. Lundberg JO, Govoni M: Inorganic nitrate is a possible source for systemic generation of nitric oxide. Free Radic Biol Med 2004, 37:395-400.

6. Cosby K, Partovi KS, Crawford JH, Patel RP, Reiter CD, Martyr S, Yang BK, Waclawiw MA, Zalos G, Xu X, et al: Nitrite reduction to nitric oxide by deoxyhemoglobin vasodilates the human circulation. Nat Med 2003, 9:1498-1505.

7. Ignarro LG: Nitric oxide as a unique signaling molecule in the vascular system: a historical overview. J Physiol Pharmacol 2002, 53:503-514.

8. Webb AJ, Patel N, Loukogeorgakis S, Okorie M, Aboud Z, Misra S, Rashid R, Miall P, Deanfield J, Benjamin N, et al: Acute blood pressure lowering, vasoprotective, and antiplatelet properties of dietary nitrate via bioconversion to nitrite. Hypertension 2008, 51:784-790.

9. Ysart G, Miller P, Barrett G, Farrington D, Lawrance P, Harrison N: Dietary exposures to nitrate in the UK. Food Addit Contam 1999, 16:521-532.

10. Hord NG, Tang Y, Bryan NS: Food sources of nitrates and nitrites: the physiologic context for potential health benefits. Am J Clin Nutr 2009, 90:1-10.

11. Santamaria P: Nitrate in vegetables: toxicity, content, intake and EC regulation. J Sci Food Agric 2006, 86:10-17.

12. Joshipura KJ, Hu FB, Manson JE, Stampfer MJ, Rimm EB, Speizer FE, Colditz G, Ascherio A, Rosner B, Spiegelman D, Willett WC: The Effect of Fruit and Vegetable Intake on Risk for Coronary Heart Disease. Ann Intern Med 2001, 134:1106-1114.

13. Joshipura KJ, Ascherio A, Manson JE, Stampfer MJ, Rimm EB, Speizer FE, Hennekens $\mathrm{CH}$, Spiegelman D, Willett WC: Fruit and vegetable intake in relation to risk of ischemic stroke. J Am Med Assoc 1999, 282:1233-1239.

14. L'Hirondel JL: Nitrate and man. Toxic, harmless or beneficial. Wallingford, United Kingdom: CABI Publishing; 2001.

15. Lundberg JO, Feelisch M, Bjorne $H$, Jansson EA, Weitzberg E: Cardioprotective effects of vegetables: is nitrate the answer? Nitric Oxide 2006, 15:359-362.

16. McKnight GM, Duncan CW, Leifert C, Golden MH: Dietary nitrate in man: friend or foe? Br J Nutr 1999, 81:349-358.

17. Bailey SJ, Winyard P, Vanhatalo A, Blackwell JR, Dimenna FJ, Wilkerson DP, Tarr J, Benjamin N, Jones AM: Dietary nitrate supplementation reduces the $\mathrm{O} 2$ cost of low-intensity exercise and enhances tolerance to high-intensity exercise in humans. J Appl Physiol 2009, 107:1144-1155.

18. Hobbs DA, Kaffa N, George TW, Methven L, Lovegrove JA: Blood pressure-lowering effects of beetroot juice and novel beetroot-enriched breads in normotensive male subjects. Br J Nutr 2012, 14:1-9.

19. Kapil V, Milsom AB, Okorie M, Maleki-Toyserkani S, Akram F, Rehman F, Arghandawi S, Pearl V, Benjamin N, Loukogeorgakis S, et al: Inorganic nitrate supplementation lowers blood pressure in humans: role for nitrite-derived NO. Hypertension 2010, 56:274-281.

20. Vanhatalo A, Bailey SJ, Blackwell JR, DiMenna FJ, Pavey TG, Wilkerson DP, Benjamin N, Winyard PG, Jones AM: Acute and chronic effects of dietary nitrate supplementation on blood pressure and the physiological responses to moderate-intensity and incremental exercise. Am J Physiol Regul Integr Comp Physiol 2010, 299:R1121-R1131.

21. Hodgson JM, Puddey IB, Burke V, Beilin LJ, Jordan N: Effects on blood pressure of drinking green and black tea. J Hypertens 1999, 17:457-463.
22. Puddey IB, Beilin LJ: Alcohol is bad for blood pressure. Clin Exp Pharmacol Physiol 2006, 33:847-852.

23. Zhang Z, Hu G, Caballero B, Appel L, Chen L: Habitual coffee consumption and risk of hypertension: a systematic review and meta-analysis of prospective observational studies. Am J Clin Nutr 2011, 93:1212-1219.

24. Larson AJ, Symons JD, Jalili T: Therapeutic potential of quercetin to decrease blood pressure: review of efficacy and mechanisms. Adv Nutr 2012, 3:49-46.

25. Staessen JA, Wang JG, Thijs L: Cardiovascular protection and blood pressure reduction: a meta-analysis. Lancet 2001, 358:1305-1315.

doi:10.1186/1475-2891-11-106

Cite this article as: Coles and Clifton: Effect of beetroot juice on lowering blood pressure in free-living, disease-free adults: a randomized, placebo-controlled trial. Nutrition Journal 2012 11:106.

\section{Submit your next manuscript to BioMed Central and take full advantage of:}

- Convenient online submission

- Thorough peer review

- No space constraints or color figure charges

- Immediate publication on acceptance

- Inclusion in PubMed, CAS, Scopus and Google Scholar

- Research which is freely available for redistribution

Submit your manuscript at www.biomedcentral.com/submit
C BioMed Central 